\title{
Química em Atividade: Participação de Educandos do Ensino Médio no Design de Jogos Digitais Educacionais Para Educação do Campo
}

\author{
Flávia M. A. Peres ${ }^{1}$, Taciana Pontual Falcão ${ }^{2}$, Dyego C. S. Morais ${ }^{3}$, Jhonatan R. S. \\ Aquino ${ }^{4}$ \\ ${ }^{1}$ Departamento de Educação, ${ }^{2}$ Departamento de Computação e ${ }^{4}$ Departamento de \\ Química, Universidade Federal Rural de Pernambuco - UFRPE, Recife-PE \\ ${ }^{3}$ Centro de Informática da Universidade Federal de Pernambuco - UFPE, Recife-PE \\ peres.flavia@gmail.com, taciana.pontual@ufrpe.br, moraisdcs@gmail.com, \\ jhonatanrafaeld13egmail.com
}

\begin{abstract}
Young students from rural areas go through difficulties through their formal education, such as lack of contextualization of curricular contents for their reality. Rural education can minimize these problems based on guidelines which favor sense-making about scientific concepts, establishing relationships with daily life, and putting the potential of transformation in evidence. This work presents results from a research about the development of digital educational games with the participation of students from a school in the rural area of the state of Pernambuco, following the DEMULTS methodology. Results point to learning of Chemistry concepts integrated with themes from the rural territory and competences in design and programming.
\end{abstract}

Resumo. Os jovens do campo vivenciam dificuldades na educação formal, como a ausência de contextualização de conteúdos curriculares para sua realidade. A educação do campo pode minimizar esses problemas a partir de diretrizes que favorecem a produção de sentidos sobre os conceitos científicos, relacionando-os ao cotidiano, e evidenciando um potencial transformador. Esse trabalho apresenta resultados de uma pesquisa sobre o desenvolvimento de jogos digitais educacionais, com a participação de educandos de uma escola da zona rural de Pernambuco, seguindo a metodologia DEMULTS. Os resultados apontam para aprendizagem de química entrelaçada ao território rural e competências em design e programação.

\section{Introdução}

Apesar da polissemia acerca da expressão Educação do Campo [Santos 2013], devido às tendências político-pedagógicas que vêm se estabelecendo por meio de diretrizes específicas, é possível apresentá-la como uma educação para "povos do campo". Esta se deu a partir de discussões, reflexões e reivindicações de movimentos sociais que defendem a ideia de um território rural, onde se pode destacar um movimento contrahegemônico que não atribui à zona rural uma área apenas produtora de mercadorias, movida pela industrialização da agricultura ou pecuária, mas sim um contexto com múltiplas dimensões onde a vida acontece, ou seja, um lugar de vida para construção de 
VII Congresso Brasileiro de Informática na Educação (CBIE 2018)

Anais dos Workshops do VII Congresso Brasileiro de Informática na Educação (WCBIE 2018)

identidades e produção de sentidos sobre a realidade. Favorecer uma percepção mediada por significados científicos, capazes de beneficiar uma vida sustentável no território rural, passa a ser a principal função da educação escolar.

As diretrizes da Educação do Campo [Caldart 2011] são documentos legais cujas linhas são compostas pela defesa de uma educação em que as situações cotidianas dos estudantes merecem ser base para as propostas educacionais que se orientem a esses sujeitos, bem como pautem-se pela luta contra a hegemonia do capital na zona rural. Porém, no geral, entendemos que as escolas situadas em zonas rurais não alcançam os ideais das diretrizes de Educação do Campo, e os materiais didáticos, assim como as representações dos conceitos, são pautados por significados que não dão conta da vida no campo, já apontado por Pavanelli (2012).

Alguns estudos mostram que os jovens rurais utilizam internet, redes sociais e já se apropriaram de muitos elementos dos contextos informatizados, transformando-se em agentes formadores de opinião da família [Aggege 2011]. De acordo com Tauk Santos e Lima (2006, p.130-131), no entanto, "o acesso aos bens materiais e imateriais se dá de forma incompleta, desigual, desvinculada". Mantêm-se, no meio rural, restrições na disponibilização de infraestrutura de acesso a produtos e serviços digitais, tornando jovens moradores destas zonas com níveis inferiores de acesso e apropriações em relação aos seus correspondentes moradores das áreas urbanas, gerando distanciamentos importantes em relação às práticas existentes no meio rural [Passarelli e Junqueira 2012]. Consideram-se, nesse cenário, necessidades de práticas e estudos que alinhem a discussão de tecnologias, como jogos digitais educacionais, considerando um usuário do campo ou um sujeito que vive em contextos rurais.

Neste trabalho, lançamos reflexões sobre essa discussão, ao propormos uma pesquisa participante em que possa ser valorizada a participação de jovens do ensino médio de uma escola situada em território rural, no desenvolvimento de jogos digitais educacionais voltados à temática da sustentabilidade. Dividido em três seções, na primeira parte discutimos a concepção de aprendizagem que orienta nossas ações, apresentando conceitos da escola de Vigotski (1988); na segunda, caracterizamos a metodologia DEMULTS, as ações dos pesquisadores na organização de Comunidades de Prática na escola, e os aspectos metodológicos do DEMULTS, que são orientados por ações de Design Participativo (DP) [Bodker et al. 2000] e Programação pelo Usuário Final (PUF) [Barbosa 1999]; em seguida, analisamos alguns enunciados ocorridos nas interações que demonstram aprendizagem de conceitos de Química e suas relações com o design da interface do jogo desenvolvido.

\section{A Abordagem Histórico-Cultural de Vigotski nas Práticas de Educação do Campo com Tecnologias}

Segundo Vigotski (1988), a aprendizagem de um sujeito precisa da interação com os outros sujeitos e com os artefatos culturais de seu tempo histórico, marcando-se pelas condições sociais de sua existência. O indivíduo sozinho, isolado de outros coespecíficos, não conseguiria se desenvolver em proporções necessárias para a aprendizagem e desenvolvimento das funções psicológicas superiores, as quais são mediadas por signos e instrumentos. 
VII Congresso Brasileiro de Informática na Educação (CBIE 2018)

Anais dos Workshops do VII Congresso Brasileiro de Informática na Educação (WCBIE 2018)

Vigotski propõe que há conhecimentos frutos da aprendizagem cotidiana, advindos de conceitos espontâneos, e outros conhecimentos que só se desenvolvem a partir de relações organizadas com fins de ensino, os conceitos científicos. A relação entre o que os sujeitos trazem de suas vivências diárias e o que a ciência construiu deve transformar-se em atividade escolar, permitindo que a abstração própria dos significados produzidos pela ciência seja internalizada e permita aos sujeitos a produção de novos sentidos sobre sua realidade concreta. Os conceitos espontâneos que seriam a bagagem de vida que cada um de nós, indivíduos, aprendemos cotidianamente em nossas interações diárias, explicam os conceitos científicos, e o mesmo acontece de forma que o científico explica os conceitos do cotidiano. Essa perspectiva une a psicologia histórico-cultural de Vigotski (1988) à Pedagogia crítica dos conteúdos, de Saviani (2000), e orienta as ações metodológicas do DEMULTS-Campo, aqui apresentadas. As tecnologias utilizadas nas atividades de desenvolvimento de jogos digitais no DEMULTS não são tomadas como "um destino" da humanidade que consequentemente deveria ser internalizado pelos sujeitos dos contextos rurais. Diferentemente, entende-se que o desenvolvimento de jogos digitais por educandos de escolas situadas no campo permite aos sujeitos a transformação das próprias tecnologias, pela apropriação das práticas de desenvolvimento das mesmas, em um processo que integra significados dos contextos de vida com significados típicos de contextos escolares, como os conceitos científicos. A ideia de apropriação é aqui entendida com base no conceito de internalização vigotskiano, que implica em algo que advém de processos interpsíquicos, ou intersubjetivos, os quais, pelas ações do sujeito, passam a integrar processos intrapsíquicos.

Vigotski (1988) chama de Zona de Desenvolvimento Proximal (ZDP) um espaço simbólico entre o nível de desenvolvimento real dos sujeitos e o nível de desenvolvimento potencial, este existindo apenas como broto, na iminência de se tornar real, mas que só com o auxílio de outros sujeitos passa a se desenvolver. É nesse espaço, a ZDP, que aqueles que ainda não desenvolveram determinadas funções psíquicas se desenvolvem para um nível real acima, ampliando o que está em potencial.

Os sujeitos em interação nas atividades escolares avançam e transformam as funções que estão em broto, a partir das relações entre seus colegas ou pares, e das relações com seus professores, ou outros participantes do processo. O papel da escola seria favorecer mediações sociais para o desenvolvimento de conceitos científicos, sendo, neste caso, a ZDP também explicativa para o que ocorre quando os conceitos espontâneos passam a ser mediados pela abstração possibilitada pela ciência e tecnologia. Porém, e é importante que se enfatize, assumimos nessa pesquisa uma tendência em não hierarquizar esses saberes (científicos e cotidianos), mas, ao contrário, permitir que o diálogo entre eles seja mais horizontal, evidenciando também o que pode ser transformado na ciência e tecnologia a partir do que emerge de situações e vivências práticas, cotidianas, espontaneamente em interações variadas.

Ciência e tecnologia são vistas, na perspectiva aqui defendida, como artefatos culturais que abrem possibilidades, mas para que esses conhecimentos somem-se à luta campesina da Educação do Campo, devem favorecer a sustentabilidade e a humanização dos sujeitos de um tempo histórico vivenciado em seus territórios de vida. $\mathrm{O}$ DEMULTS-Campo, usando abordagens participativas de DP e PUF, soma-se na defesa da apreensão de tecnologias por jovens do ensino médio, para que a partir de jogos 
VII Congresso Brasileiro de Informática na Educação (CBIE 2018)

Anais dos Workshops do VII Congresso Brasileiro de Informática na Educação (WCBIE 2018)

típicos de seu tempo aprendam conceitos científicos de disciplinas escolares, relacionem-os ao seu cotidiano e, ainda, se apropriem de ferramentas sígnicas existentes nas áreas de programação e design.

É defendido amplamente que jogos educativos têm cada vez mais seu espaço conquistado na aprendizagem escolar, de forma que a ludicidade à qual os educandos são submetidos nos jogos faça com que o aprendizado se torne cada vez mais divertido [Yang e Chang 2013]. No entanto, se esses materiais como jogos digitais não estiverem integrados a um projeto pedagógico mais amplo, com ações que promovam o desenvolvimento real dos sujeitos, podem não levar à aprendizagem de conteúdos. Mais ainda, quando se trata de uma educação para os povos do campo, refletimos que a imposição de jogos digitais criados a partir de exemplos tipicamente advindos de uma cultura urbana e sem relação com o contexto campesino acaba por não favorecer a reflexão sobre o cotidiano e a vida em territórios rurais.

Desde 2011, o DEMULTS vem sendo aplicado em escolas públicas urbanas [Pontual Falcão et al. 2017, 2018]. No primeiro ciclo do DEMULTS-Campo, aqui relatado, duas adaptações do modelo nas atividades em contexto de educação do campo foram aplicadas, para compreender a aprendizagem sobre os conceitos científicos, ao longo do processo. São elas: a inclusão de um professor de Química que atua em uma escola de educação do Campo diferente do locus da pesquisa; e a imersão em situações práticas para produção de sentidos sobre $\mathrm{pH}$ do solo e decomposição orgânica.

\section{Metodologia}

O DEMULTS vem utilizando-se de uma metodologia que projeta os jogos para além da ênfase na ludicidade, buscando promover a apropriação dos modos de produção. Os usuários potenciais, neste ciclo DEMULTS-Campo educandos do ensino médio da zona rural, produzem seu próprio jogo digital e com isso aprendem tanto o conteúdo escolar abordado no jogo, quanto significados subjacentes à lógica de programação e design dessas ferramentas. O processo de desenvolvimento dos jogos digitais passa a ser fundamental à aprendizagem dos conceitos, tornando-se, ao mesmo tempo, processo-produto de aprendizagem. Durante o processo, os educandos se engajam em atividades interativas, criadas no contexto escolar como Comunidades de Prática (CP) [Lave e Wenger 1991], em que vivenciam com especialistas em Design, Programação e em conteúdos curriculares específicos - neste ciclo relacionados à Química - um contexto típico de desenvolvedores de jogos digitais, com intensas trocas dialógicas. Uma $\mathrm{CP}$ reúne pessoas com diferentes níveis de conhecimento $\mathrm{e}$ competências (chamados de especialistas e novatos), que compartilham um objetivo comum e interagem para atingi-lo colaborativamente. Para a concretização dos objetivos de sua CP, o DEMULTS utiliza DP [Bodker et al. 2000] e PUF [Barbosa 1999], para que educandos novatos na comunidade de prática desenvolvam jogos digitais cujos usuários pressupostos são eles próprios, seus pares e outros usuários com perfis semelhantes. Pelo DP, os participantes são co-criadores, e produzem significados com base em seus próprios sentimentos e atitudes para o artefato [Bodker et al. 2000].

A pesquisa realizada no DEMULTS é portanto participante, com intervenções dos pesquisadores no contexto de uma escola no Ensino Médio, que neste ciclo está situada na zona rural de Pernambuco. No atual ciclo, a equipe era composta de cinco 
pesquisadores: dois especialistas em programação; dois especialistas em Química; e um especialista em Design. Houve ainda outros colaboradores do projeto que se responsabilizaram mais pelas questões éticas e burocráticas com a escola e os educandos, e na Comunidade de Prática colaboraram na organização da agenda de encontros e relações institucionais.

A escola, locus da pesquisa, foi escolhida a partir de uma lista de 70 escolas, consideradas "escolas estaduais do campo" a partir de diálogo com a Secretaria de Educação do Estado de Pernambuco. Entre as escolas "certificadoras rurais" da lista (ou seja, que passaram por capacitações para a educação do campo), foram considerados aspectos como mobilidade dos pesquisadores e receptividade da gestão da escola para a escolha. A aplicação do DEMULTS teve as seguintes fases:

Apresentação: após uma apresentação dialogada com slides, aplica-se um questionário para verificar habilidades, interesses, e outras características amplas que já foram verificadas em ciclos anteriores do DEMULTS como sendo importantes para a participação e engajamento.

Delimitação temática e conceitual do jogo: neste ciclo, foi introduzida esta etapa de contato com um "cliente real", para quem deveria ser desenvolvido o jogo digital educacional. Esse cliente foi um professor de Química do ensino médio, de uma outra escola do campo, situada em Orobó-PE, que tem interesse em jogos para ensinar conteúdos curriculares aos seus educandos. Esse professor sugeriu algumas temáticas com conteúdos considerados de difícil explanação e contextualização com o cotidiano dos educandos. Após a apresentação do cliente aos novatos, estes entre si, e em discussões com os especialistas de Química, elegeram o tema "Compostagem".

Imersão: esta etapa realiza-se em contexto de prática, com aplicação de conceitos e técnicas relacionados ao tema escolhido. Como o tema foi Compostagem, os conceitos relacionados centralizaram-se sobre conteúdos de química como $\mathrm{pH}$ do solo. Para imersão propriamente dita, os educandos vivenciaram na escola o desenvolvimento de uma composteira. Com o andamento da composteira houve a imersão no conceito e, concomitantemente, partiu-se para o desenvolvimento da mídia.

Desenvolvimento: inicialmente, há um momento de brainstorming, em que com a mediação dos especialistas desenvolvedores os educandos novatos vão livremente elencando palavras relacionadas ao tema central do jogo e à própria mecânica do jogo. Inicia-se então o processo de prototipagem por meio de storyboard. Logo após a definição da narrativa do jogo inicia-se a construção do jogo com as equipes de programação e design, assessorados pelos especialistas em Química. Toda a construção do jogo conta com auxílio dos especialistas, sendo suas vozes muito importantes no tocante aos conteúdos, para a representação mais correta desses na interface.

Aplicação: apresentação ao cliente e testes com educandos da escola pelos desenvolvedores novatos. Nesse ciclo, a versão beta foi apresentada ao cliente, mas ainda será testada com educandos.

O processo como um todo é objeto de estudo nesta pesquisa participante aqui apresentada. Especificamente, focalizamos as interações dos educandos relacionadas aos conceitos científicos e espontâneos da compostagem: pH do solo e decomposição orgânica, e sua organização na interface do jogo. Para a construção de dados, realizamos 
VII Congresso Brasileiro de Informática na Educação (CBIE 2018)

Anais dos Workshops do VII Congresso Brasileiro de Informática na Educação (WCBIE 2018)

questionários, entrevistas, observações participantes e videografias de todo o processo. Para a análise dos dados, deu-se um olhar eminentemente qualitativo, amparado por elementos de uma análise discursiva enunciativa [Bakhtin 1994], em que se buscaram os jogos dialógicos no espaço simbólico da ZDP, entre novatos e novatos, novatos e especialistas, novatos e cliente. Os enunciados que dialogam com a construção do conceito de $\mathrm{pH}$ e decomposição orgânica são nossa unidade de análise, envolvendo relações científicas e cotidianas entre os significados.

\section{Resultados e Discussões}

Todos os 25 educandos que demonstraram interesse em participar do DEMULTS nos questionários iniciais foram selecionados. No entanto, apenas 9 permaneceram engajados até o início da fase de desenvolvimento do jogo; e apenas dois educandos permaneceram até a apresentação do jogo ao cliente, sendo estes dois os que de fato estiveram presentes e engajados em todo o processo. Os motivos do engajamento e desengajamento já foram estudados em outros ciclos [Pontual Falcão et al. 2018], mas merecem novas considerações específicas do contexto rural. Entretanto, não sendo objetivos deste artigo, não serão aqui explorados.

Apesar disso, pudemos identificar momentos de trocas enunciativas de produção de sentidos por parte dos educandos, que indicam que houve aprendizagem sobre os conceitos científicos de $\mathrm{pH}$ do solo e de decomposição orgânica, muito relacionada ao processo vivenciado de construção de uma composteira, que foi determinante para a narrativa do jogo digital desenvolvido. Muitos aspectos da prática vivenciada foram fundamentais para solucionar questões de design, favorecendo dialeticamente tanto a aprendizagem de conceitos científicos de química quanto ações de design da interface.

O momento de apresentação das necessidades pelo cliente mostrou-se relevante para o processo. Percebemos que os educandos ficaram atentos às propostas sugeridas pelo professor cliente. Uma das novatas, a educanda V., observou atentamente o que estava sendo proposto pelo cliente e iniciou o debate sobre qual dos temas seria escolhido, informando aos outros que dentre os temas propostos, a compostagem teria boa parte dos outros conteúdos, e assim se ampliariam os subtemas de química do jogo. Os temas propostos pelo professor cliente, foram interpretados pela educanda, em categorias atribuídas por ela mesma a partir dos enunciados do professor, traduzindo para suas próprias palavras, em seu celular, os tópicos sugeridos para serem temas do jogo: 1. ph do solo; acidez e alcalinidade; correção do solo. 2. adubo organico (compostagem); reações químicas. 3. bioquímica; bactérias fixadoras de nitrogênio; etapas e ciclo (do nitrogênio) e como o homem interfere nesse ciclo; adubação verde. 4. agrotóxicos; conscientizar sobre suas implicações de uso reações orgânicas $e$ substâncias. Esse jogo entre as palavras do professor, carregadas de enunciados científicos, e as palavras da educanda, dialogada com o que o professor apresentou, apontam um processo de ZDP, em que o nível da educanda potencial para a aprendizagem de conceitos científicos é evidenciado.

O processo de construção da composteira, para uma imersão no conteúdo, foi uma novidade no atual ciclo do DEMULTS, considerando-se que em ciclos anteriores, ocorridos de 2011 a 2016 [Pontual Falcão et al. 2017, 2018], não havia um momento de imersão nos conceitos científicos a serem focalizados no desenvolvimento do jogo, 
VII Congresso Brasileiro de Informática na Educação (CBIE 2018)

Anais dos Workshops do VII Congresso Brasileiro de Informática na Educação (WCBIE 2018)

precedendo esse desenvolvimento. Deste momento, pudemos observar que houve engajamento e interação entre novatos e especialistas para criação da composteira.

Entre as ações previstas, os novatos ficaram designados a passar informação aos demais educandos da escola sobre coleta de lixo, convocando-os à coleta seletiva. Foram elaboradas placas para colocar no coletor de alimentos, mostrando qual tipo de alimento poderia ser colocado no recipiente. Nesse contexto, discutiu-se sobre lixo e sobre quais restos poderiam ser aproveitados na composteira, ampliando a ZDP também para outros sociais presentes em livros didáticos e sites na internet, a partir das pesquisas em busca de uma compreensão de quais restos poderiam favorecer o processo de compostagem. Identificamos que os enunciados deste momento não foram mediados por conceitos científicos como os direcionados ao $\mathrm{pH}$ do solo, ou à decomposição orgânica, mas favoreceram os conceitos cotidianos, pela vivência prática que preparava o terreno para dar sentido aos significados científicos.

As relações do conceito de $\mathrm{pH}$ do solo com os conceitos cotidianos espontaneamente emergentes nas atividades para construção da composteira foram sendo desenvolvidas através da aprendizagem dos conceitos científicos, e pudemos verificar a ampliação da ZDP nos novatos engajados durante todo ciclo. Os impactos da construção da composteira sobre o processo já se fizeram sentir no momento do brainstorming, onde os novatos se mostraram bastante motivados para atividade com os temas sugeridos, ativamente levantando enunciados sobre os temas propostos.

\subsection{Desenvolvimento do jogo}

O storyboard com as fases do jogo foi construído tendo em vista um usuário que deveria, ao jogar, aprender conceitos relacionados ao processo químico que ocorre na compostagem, uma das sugestões do professor cliente. O jogo dialógico dava-se convocando esse usuário pressuposto, como elo na cadeia discursiva que só se atualizaria no momento de uso, propriamente dito, que deveria ser a prática desse professor com outros estudantes do ensino médio, com um material jogável e educativo. Mecânica e narrativa foram discutidas em um processo que evidenciou muitos enunciados em interação especialistas-novatos e novatos-novatos, para chegarem às definições das fases e suas relações com conceitos científicos solicitados pelo cliente.

$\mathrm{Na}$ narrativa proposta, a minhoca Californiana (nome que faz referência ao tipo de minhoca pertencente à composteira) era a personagem principal. Os traços do desenho representativo dessa minhoca atendem às suas particularidades reais, mediando-se o desenho por conceitos científicos (coloração e estrutura corporal). A minhoca parte em uma aventura para conseguir itens para construção de uma composteira, tal qual os educandos vivenciaram no processo de imersão conceitual. Na primeira fase, ela enfrenta uma enchente saltando em plataformas para juntar água em um balde. Na fase seguinte, a minhoca segue para uma terra seca e quente para coletar areia para composteira. Na terceira fase, a minhoca, controlada pelo usuário, tem $\mathrm{o}$ desafio de coletar frutas que caem do topo da tela para regular o $\mathrm{pH}$ do solo, que está ácido demais e precisa ficar neutro (atingindo $\mathrm{pH}$ 7).

Observamos nesse processo várias passagens de enunciados dos educandos que explicitam os momentos da imersão no desenvolvimento da composteira. A própria ideia de um reino de minhocas foi decorrente do desenvolvimento da composteira, em 
VII Congresso Brasileiro de Informática na Educação (CBIE 2018)

Anais dos Workshops do VII Congresso Brasileiro de Informática na Educação (WCBIE 2018)

que uma das dificuldades foi conseguir minhocas para agilizar o processo de decomposição e alteração do $\mathrm{pH}$. Assim, evidenciam-se nessa etapa de desenvolvimento do jogo muitos significados nos enunciados que atestam aprendizagem de química, na correlação entre o potencial hidrogeniônico das frutas com o solo, e o processo de compreensão sobre a construção de uma composteira.

A Figura 1 (esquerda) mostra o caderno de um novato que organiza os conceitos de como a barra de $\mathrm{pH}$ seria representada na interface do jogo, relacionando conceitos científicos com design de interface. Pode-se observar que os conceitos sobre ácido e base foram desconstruídos e reconstruídos por relacionarem-se com significados científicos centrais para compreensão dos conceitos de $\mathrm{H}+$ para acidez, e $-\mathrm{OH}$ para alcalinidade. Assim, tivemos a evolução de um nível potencial na ZDP, adquirido na vivência de desenvolvimento da composteira, em que emergiram conceitos espontâneos, para um nível real de conceituação científica, aprendido pela interação com especialistas para favorecer os conceitos de química, propriamente ditos. A Figura 1 (direita) mostra a interface dessa fase do jogo, com os detalhes da barra de $\mathrm{pH}$ e de várias frutas que caem para a minhoca poder balancear o $\mathrm{pH}$ do solo. A escolha das frutas, atentando para o balanceamento do $\mathrm{pH}$ e todos os significados científicos que permearam essa escolha, são fortes indicadores da inter-relação da aprendizagem de design participativo e conteúdos escolares, encapsulando-se na organização da interface pelos educandos participantes. As frutas foram escolhidas e desenhadas pelos educandos, e o comportamento da minhoca também foi programado por eles, com auxílio dos especialistas.

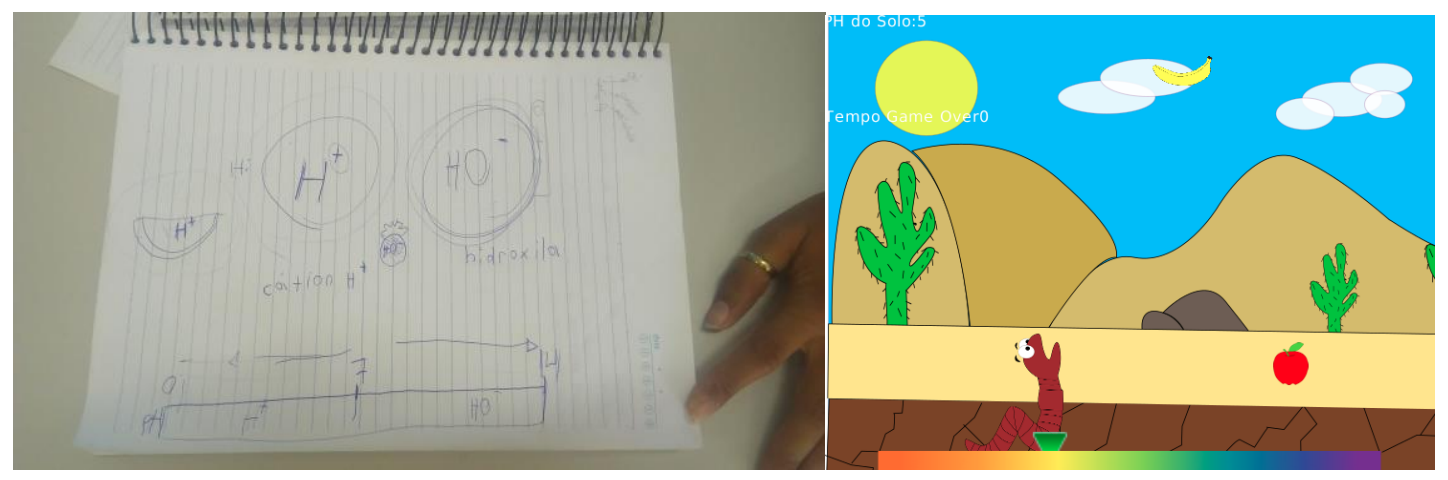

Figura 1. À esquerda, anotações dos educandos sobre barra de $\mathrm{pH}$ e frutas do jogo. À direita, interface da fase 3 do jogo, com a barra de pH na parte inferior.

\subsection{Apresentação do jogo}

Uma versão beta do jogo foi apresentada ao professor cliente, e foi possível constatar nesse momento o domínio do conteúdo de química aplicado no jogo pela educanda R., invocando conceitos científicos e relacionando-os com o processo cotidiano vivenciado no DEMULTS. Já o educando W. criou simbologia sobre o conteúdo, uma espécie de mediação simbólica para a representação do conceito científico na interface, demonstrando saber como funciona o movimento da barra de $\mathrm{pH}$ no jogo. Entretanto, não soube explicar o conceito de $\mathrm{pH}$ : sabia que a acidez faz com que o valor diminua e a alcalinidade/basicidade aumente, mas ainda não conseguia relacionar com os conceitos científicos e cotidianos. Em contrapartida, W. demonstrou apropriação de ações para programação em blocos, e conseguiu resolver problemas de design e programação 
articuladamente, para o funcionamento da barra de $\mathrm{pH}$. Pudemos perceber ao longo dos encontros sua motivação, aptidão e desejo pela prática de desenvolvimento de jogos digitais, pois começou a fazer um outro jogo por conta própria.

O professor cliente, em interação com os novatos no momento da apresentação do jogo, produziu enunciados que demonstraram satisfação com a forma como o conteúdo foi organizado na interface e com potenciais usos, como: "A fase apresentada é uma excelente forma que pode ser usada para explicar os conceitos de $\mathrm{pH}$ em sala de aula, devido à ludicidade do jogo, e os educandos verem o que acontece realmente na prática na barra de $\mathrm{pH}$, a qual só veem teoricamente em sala de aula, devido ao fato de que nem todas as escolas dispõem de laboratórios químicos para prática laboratorial." Ele também indagou sobre a escolha do tema $\mathrm{pH}$ do solo e compostagem, ao que a educanda $\mathrm{R}$. relembrou enunciados que remetiam à atividade de imersão. Disse que a escolha tinha se dado porque viram que havia diferentes tipos de terra no solo da escola, com areias de cores diferentes, e que a ideia era balancear o $\mathrm{pH}$ desse solo para poder desenvolver uma horta, no futuro. Observamos nesse enunciado uma compreensão sobre $\mathrm{pH}$ do solo a partir de relações com o cotidiano e suas vivências, e o quanto a atividade de imersão parece ter favorecido esse processo de relação entre conceitos científicos e cotidianos, e entre as vozes dos novatos e especialistas.

\section{Considerações Finais}

A metodologia DEMULTS, que tem vários ciclos [Pontual Falcão et al. 2017, 2018], foi adaptada no ciclo aqui apresentado ao contexto da zona rural, para favorecer mediações científicas aos jovens desse território, com um olhar para a sustentabilidade; e dialogar com professores de ensino médio de escolas do campo, para inserção de materiais didáticos que favoreçam exemplos e discussões típicas desse contexto em suas práticas. A apresentação do jogo para um cliente, somada à fase de imersão conceitual, foram as duas principais inovações, e mostraram, pelas análises, representar uma adequação necessária à educação do campo, favorecendo a apropriação de conceitos que beneficiem uma percepção dos jovens do campo mediada pelo seu cotidiano.

A fase de imersão ajudou a superar duas barreiras percebidas em ciclos anteriores: a defasagem de aprendizagem dos educandos em relação ao seu ano escolar; e a percepção de conteúdos científicos como entendiantes e desconectados da realidade dos educandos [Pontual Falcão et al., 2017]. Os especialistas tiveram um papel-chave no favorecimento de relações entre os conceitos científicos referentes ao conteúdo escolhido e o cotidiano, para que a criação do jogo se desse de forma a beneficiar os novatos à apropriação de conhecimentos científicos contextualizados. A apresentação do protótipo do jogo ao cliente foi reveladora de duas ações de aprendizagem no processo: uma aprendizagem mais técnica-operacional, enunciada pelo educando W., que dialoga com vozes de designers e programadores; e uma aprendizagem mais conceitual, da educanda R., que apesar de dialogar com programadores, aponta em seus enunciados um forte diálogo com as vozes dos especialistas em química. Além disso, reforçou-se a importância do envolvimento efetivo e afetivo dos especialistas no processo para a motivação dos novatos [Pontual Falcão et al., 2017].

Ainda assim, permanecem os questionamentos acerca de evasão e motivação, e pretende-se, nas entrevistas finais e estudos futuros, verificar o que favoreceu, neste 
VII Congresso Brasileiro de Informática na Educação (CBIE 2018)

Anais dos Workshops do VII Congresso Brasileiro de Informática na Educação (WCBIE 2018)

ciclo, o perfil motivacional dos educandos R. e W., atuando em suas ZDPs, e resultou em aprendizagens diferentes, e como podemos favorecer mais ações que beneficiem o desenvolvimento do perfil de R., que articula mais apropriadamente os conceitos científicos, para um nível real de desenvolvimento, em relação com os cotidianos.

\section{Referências}

AGGEGE, S. (2011) O poder da maioria. In: Revista Carta Capital, São Paulo: 4 de maio de 2011 ano XVI n ${ }^{\circ} 644$ p. 18-22.

BARBOSA, S. D. (1999) Programação via Interface. (Doctorate), Pontifícia Universidade Católica do Rio de Janeiro, Rio de Janeiro.

BODKER, S.; EHN, P.; SJÖGREN, D.; SUNBLA, Y. (2000) Co-operative design perspectives on 20 years with 'the scandinavian IT design model'. In Proc. of the nordic conference on human-computer interaction - NordiCHI, Stockholm.

BAKHTIN, M. (1994) Estética da criação verbal. São Paulo: Martins Fontes.

CALDART, R. S. (2011) Dicionário da Educação do Campo. (Org.) Rio de Janeiro: IESJV, Fiocruz, Expressão Popular.

LAVE, J.; WENGER, E. (1991) Situated Learning: Legitimate peripheral participation. Cambridge: Cambridge University Press.

PAVANELLI, J. A. P. (2012) Educação do campo e ensino de ciências: Desafios e propostas a partir de princípios agroecológicos. Monografia (Monografia de Estágio Curricular), Instituto de Biociências de Botucatu - UNESP/SP.

PASSARELLI, B. e JUNQUEIRA, A. H. (2012) Gerações Interativas Brasil - Crianças e Adolescentes diante das telas. São Paulo: Escola do Futuro/USP. 352 p.

PONTUAL FALCÃO, T.; OliVEIRA, G. S.; PERES, F. M. A.; MORAIS, D. C. S. (2017) Design Participativo de Jogos Digitais Educacionais por Adolescentes Imersos em uma Comunidade de Prática. Revista Sistemas e Computação, v.7, pp. 189-205.

PONTUAL FALCÃO, T.; PERES, F. M. A.; MORAIS, D. C. S., OLIVEIRA, G. S. (2018) Participatory methodologies to promote student engagement in the development of educational digital games. Computers \& Education, 116, p.161-175.

SANTOS, C. F. (2013) O "aprender a aprender" na formação de professores do campo. Campinas SP: Autores Associados

SAVIANI, D. (2000) Pedagogia histórico-crítica: primeiras aproximações. - $9^{\mathrm{a}}$ ed. Campinas SP: Autores associados.

TAUK SANTOS, M. S. e LIMA, M. (2006) Desafios cooperativos e estratégias de comunicação das incubadoras tecnológicas cooperativas populares. In: Revista Unircoop. Vol.4, $\mathrm{n}^{\circ} 1$.

VIGOTSKI, L. S. (1988) A formação social da mente. São Paulo, Martins Fontes.

YANG, Y.-T. C.; CHANG, C.-H. (2013) Empowering students through digital games authorship: Enhancing concentration, critical thinking and academic achievement. Computers and Education, 68, 334-344. 